\title{
Primary tumorous aldosteronism due to a black adrenal adenoma: a light and electron microscopic study
}

\author{
IK SIENKOWSKI, RM WATKINS, VER ANDERSON \\ From the Departments of Morbid Anatomy and Surgery, King's College Hospital, Denmark Hill, London \\ SE5, and the Department of Histopathology, Dulwich Hospital, East Dulwich Grove, London SE22
}

SUMMARY A case of primary tumorous aldosteronism due to a black adrenal adenoma in a 37-year-old man is reported. Light microscopy showed the tumour to consist predominantly of compact cells containing intracytoplasmic lipofuscin, accompanied by zona fasciculata and intermediate type cells. Electron microscopy identified compact and interface (inner zona fasciculata) type cells, and also demonstrated spironolactone bodies in a compact cell. The morphological appearance of the tumour and adjacent adrenal gland, combined with the clinical and biochemical findings, supports both its secretory function and its classification as a rare variant of the more common non-pigmented aldosteronoma.

Pigmented lesions of the adrenal gland include myelolipoma, metastatic melanoma, haemangioma and haematoma. These can be readily excluded histologically and histochemically leaving two pigmented lesions exclusive to the adrenal, the pigmented nodule and the black adenoma. ${ }^{12}$

Pigmented nodules were thought to be rare until Robinson et $\mathbf{l}^{3}$ demonstrated their presence in 37 of 100 consecutive necropsy adrenals. No association was found with hypertension, altered serum electrolytes or other evidence of endocrine dysfunction. The lesions were labelled nodules to distinguish them from adenomas which are true neoplasms. They are thought to be a pigmented equivalent of the yellow nodules commonly found at necropsy, whose cells do not produce significant amounts of steroids in vivo although able to do so in in vitro monolayer cell culture.'

In contrast the black adenoma is a true neoplasm with a dark brown or black cut surface capable of producing steroids and hypercorticalism. Although several causing Cushing's syndrome have been reported, ${ }^{4-10}$ there is only one previous report of associated aldosteronism."

Requests for reprints to: Dr IK Sienkowski, Department of Histopathology, Mayday Hospital, Thornton Heath, Croydon, England.

Accepted for publication 15 September 1983.

\section{Case report}

The patient, a 37-year-old black man, had been hypertensive for seven years and treated with $\beta$-blockers and diuretics. On further investigation he was found to be hypokalaemic. The serum aldosterone level was raised $(200 \mathrm{nmol} / \mathrm{l}$; $\mathrm{NR}<140 \mathrm{nmol} / \mathrm{l}$ ) and the supine plasma renin activity was subnormal $(50 \mathrm{pg} / \mathrm{ml} / \mathrm{h} ; \mathrm{NR}=300$ $1300 \mathrm{pg} / \mathrm{ml} / \mathrm{h})$. ${ }^{75} \mathrm{Se}$-selenomethylcholesterol scanning ${ }^{12}$ showed increased uptake by the right adrenal gland (Table 1). A CT scan demonstrated a $2.5 \mathrm{~cm}$ $\times 2.0 \mathrm{~cm}$ lesion in the right adrenal gland. The left adrenal appeared normal. Eleven months prior to surgery the patient started treatment with spironolactone $200 \mathrm{mg}$ daily and all other medication was stopped. Blood pressure was well controlled but marked bilateral gynaecomastia developed as a side effect of this therapy. At laparotomy a normal left adrenal gland was identified. The right adrenal was enlarged by the presence of an encapsulated black tumour measuring $2.5 \mathrm{~cm} \times 2.5 \mathrm{~cm} \times$ $2.0 \mathrm{~cm}$. A standard right adrenalectomy was performed. The patient's recovery was uneventful and after one year he has remained normotensive requiring no medication.

\section{PATHOLOGY}

The specimen consisted of the right adrenal gland $4.0 \mathrm{~cm} \times 2.5 \mathrm{~cm} \times 2.0 \mathrm{~cm}$ with a tan coloured 
Table $1{ }^{75}$ Se-selenomethylcholesterol scan

\begin{tabular}{lll}
\hline & Right adrenal & Left adrenal \\
\hline 7 days & $0.45 \%$ & $0.09 \%$ \\
14 days & $0.48 \%$ & $0.10 \%$ \\
\hline
\end{tabular}

Normal uptake $0 \cdot 07-0.3 \%$

tumour partially invested in fat, in the form of a flattened disc $2.5 \mathrm{~cm} \times 2.5 \mathrm{~cm} \times 2.0 \mathrm{~cm}$ arising from its medial surface. The cut surface of the tumour was blackish-brown with small focal pale areas and bounded by a capsule (Fig. 1). The adrenal gland showed no macroscopic nodularity.

The specimen was received in $10 \%$ formol saline. Blocks from the tumour and the adrenal gland, cut transversely at approximately $2 \mathrm{~mm}$ intervals, were sectioned routinely and stained with haematoxylin and eosin, Luxol fast blue and the special stains listed in Table 2. Small blocks up to $0.5 \mathrm{~cm} \times$ $0.5 \mathrm{~cm} \times 0.1 \mathrm{~cm}$ were also taken from the tumour and transferred into Trump's fluid ${ }^{13}$ approximately five months after initial receipt of the specimen, postfixed in $1 \%$ osmium tetroxide in distilled water and embedded in Polarbed 812 resin. Sections $(0.5 \mu \mathrm{m})$ were cut and stained with toluidine blue. Thin sections were cut on a Cambridge Huxley Mk II ultramicrotome and examined on a Corinth electron microscope (AEI 275).

Microscopic examination of the adrenal was confined to a distance of $1.8 \mathrm{~cm}$ adjacent to the tumour.

\section{LIGHT MICROSCOPY}

Sections showed a rounded cellular tumour bounded by a narrow rim of cortical tissue continuous with
Table 2 Histochemical reactions of pigment granules

\begin{tabular}{lll}
\hline Stain & $\begin{array}{l}\text { Control } \\
\text { (lipofuscin) }\end{array}$ & Adenoma \\
\hline Long Ziehl-Neelsen & + & - \\
Perl's & - & - \\
Schmorl & + & ++ \\
Periodic acid Schiff & + & \pm \\
Masson-Fontana & + & + \\
Giemsa & + & + \\
Sudan black & + & \pm \\
Haematoxylin and eosin & + & + \\
\hline
\end{tabular}

the adjacent adrenal gland and invested by a fibrous capsule. The rim of cortical tissue was narrower distally and absent for one quarter of the tumour circumference opposite its adrenal attachment. Tumour cells abutted directly onto the adrenal capsule in this region. A few compact cells extended beyond the capsule into the periglandular adipose tissue. The fibrous capsule was poorly developed between the tumour and the adjacent adrenal. The subcapsular rim of adrenal cortex broadly retained normal zonation but zona glomerulosa cells formed hyperplastic clusters which projected into the underlying tumour. Most of the zona glomerulosa cells contained spironolactone bodies.

The tumour comprised compact cells and lipid containing zona fasciculata and intermediate cells (Fig. 2). Compact cells, the commonest, were polygonal and arranged in sheets, cords and alveoli separated by fibrovascular spaces. Nuclei were vesicular, mildly pleomorphic and contained nucleoli and a few inclusions. Mitoses were infrequent (2 per 10 high power fields). Many cells were larger than typical compact cells and a few were bi-, tri- or tetra-nucleate. The cytoplasm was eosinophilic and

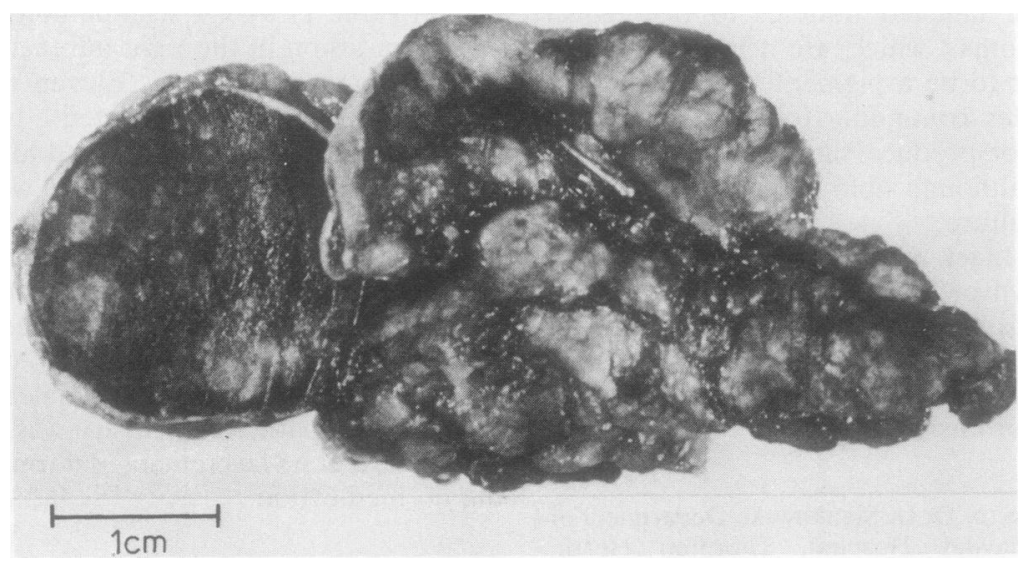

Fig. 1 The surgical specimen, showing the adenoma with characteristic black cut surface. A pale rim of flattened cortical adrenal tissue can be seen on the periphery of the tumour. The surface of the adjacent adrenal is largely obscured by fat. 


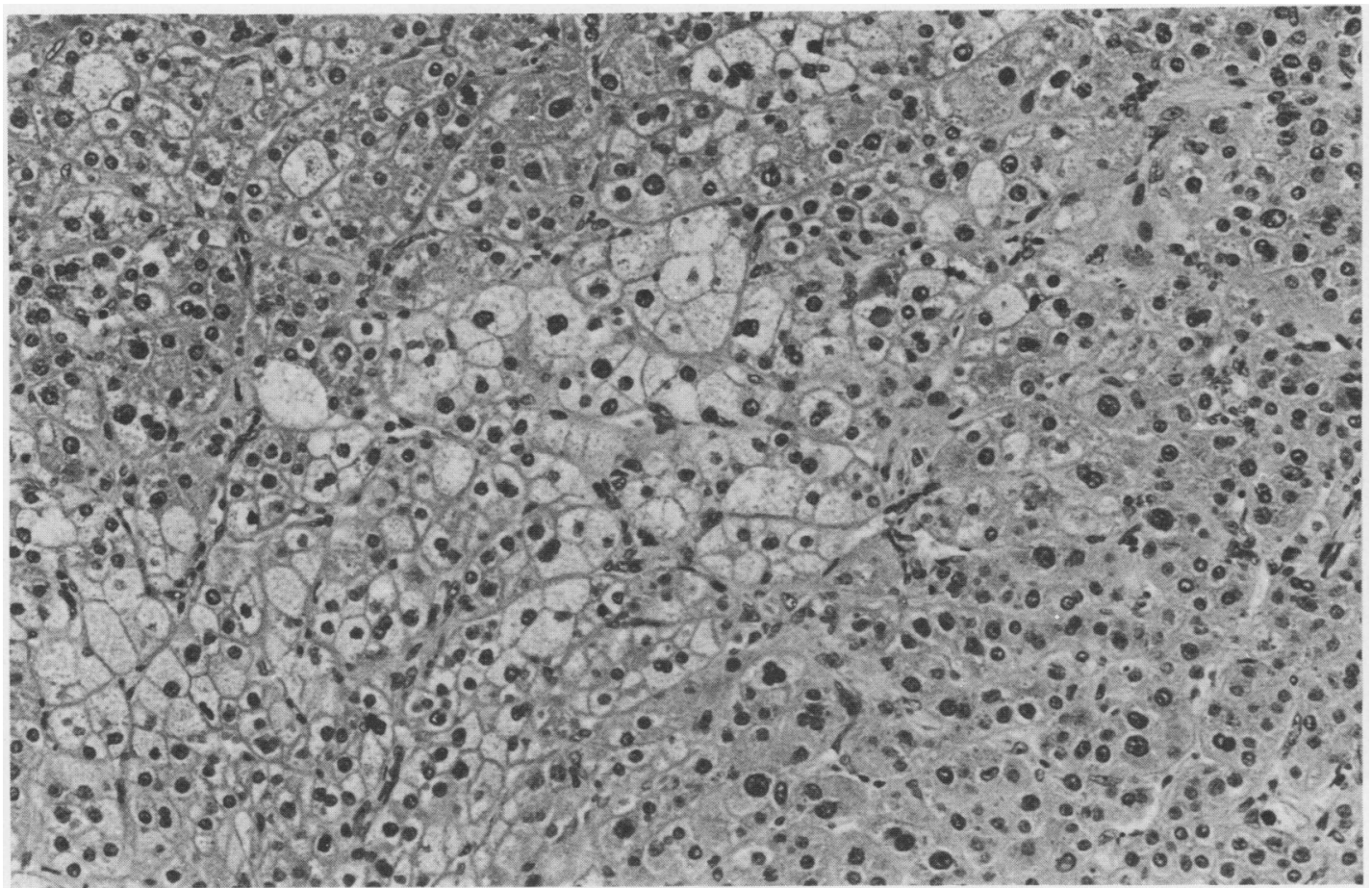

Fig. 2 Photomicrograph of the black adenoma showing sheets of pigmented compact cells interspersed with clusters of clear zona fasciculata and intermediate type cells mainly occupying the upper left and central portions of the picture. Haematoxylin and eosin $\times 280$.

contained fine to coarse reddish-brown granules which stained as late reducing lipofuscin. The zona fasciculata cells possessed vesicular, mildly pleomorphic nuclei and clear cytoplasm with a low nuclear-cytoplasmic ratio. They formed small clusters and cords closely associated with intermediate cells which were smaller with higher nuclearcytoplasmic ratios. Both types of clear cell also contained small numbers of lipofuscin granules. The tumour also contained several extracellular lipid accumulations and thin-walled blood vessels. There was no evidence of malignancy. Spironolactone bodies were not seen by light microscopy despite staining with Luxol fast blue.

The adrenal gland contained a few cortical micronodules exclusively composed of zona fasciculata cells, the largest measuring $0 \cdot 14 \mathrm{~cm}$ (Fig. 3). Their appearance conformed to the criteria of Ferris et al ${ }^{14}$ for non-functioning nodules. Extensive prominent diffuse hyperplasia of the zona glomerulosa (Fig. 4) with focal downgrowths was present. Spironolactone bodies which were numerous in the zona glomerulosa cells were also seen in a few zona fasciculata cells. Focal lipid depletion interspersed with compact cells forming a reversion pattern was present.

\section{ELECTRON MICROSCOPY}

Tissue preservation was patchy and generally poor due partly to delay in the use of the appropriate fixative. Electron microscopy showed sheets of closely apposed cells bounded by a narrow interstitial space with an intervening basement membrane. The space contained diffuse collagen fibres. One vessel was seen which showed a uniformly thick endothelium. Two cell types, compact and interface (inner zona fasciculata), were identified at the tumour periphery. The compact cells (Fig. 5) contained round indented nuclei with occasional nucleoli. The plasma membrane was moderately folded with numerous microvilli. Mitochondria were rounded with tubulovesicular or tubular cristae. Prominent in the cytoplasm were discrete rounded electron dense bodies which also formed aggregates. Slightly fewer than half contained rounded lucencies resembling lipid. Their appearances were consistent with those of lysosomes. Pigment bodies were scant. Stacked and fragmented rough endoplasmic reticulum and free ribosomes were present. Smooth endoplasmic reticulum formed densely packed small vesicles. A single compact cell contained at least three fragmented intracytoplasmic bodies character- 


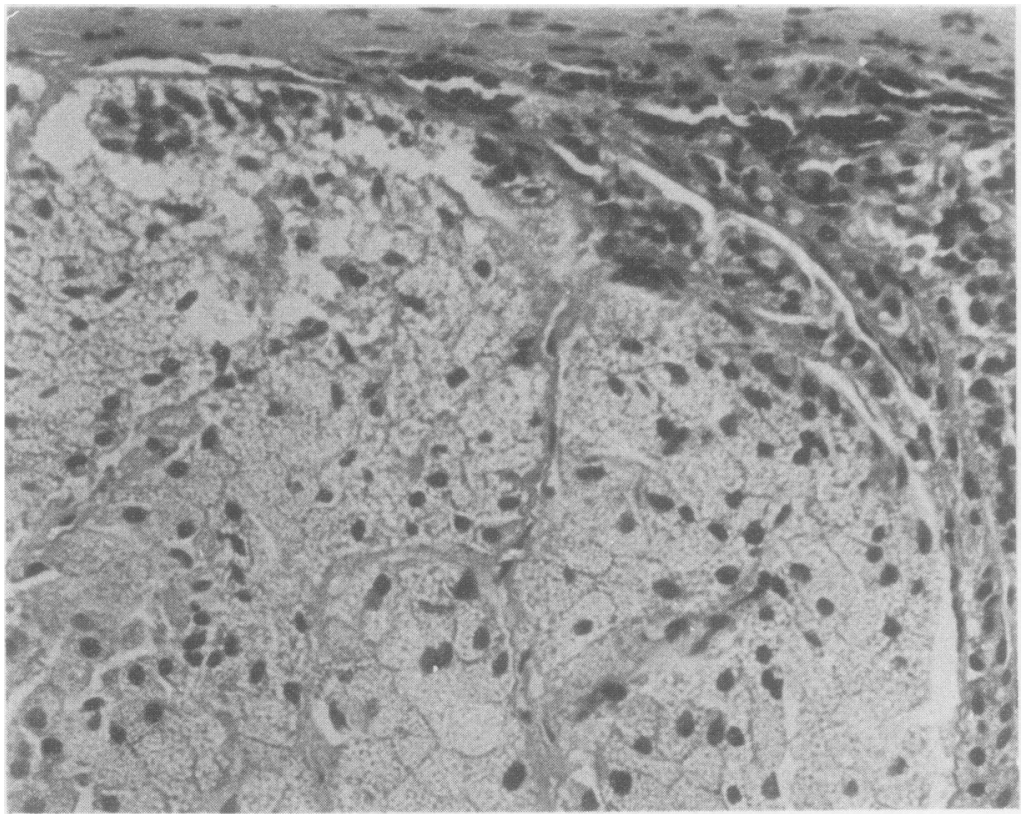

Fig. 3 A portion of a clear cell micronodule in the cortex of the adjacent gland. This was the largest nodule seen and consists exclusively of zona fasciculata cells. The adrenal capsule is visible at the upper margin. Note the minimal nuclear pleomorphism. Haematoxylin and eosin $\times 441$.

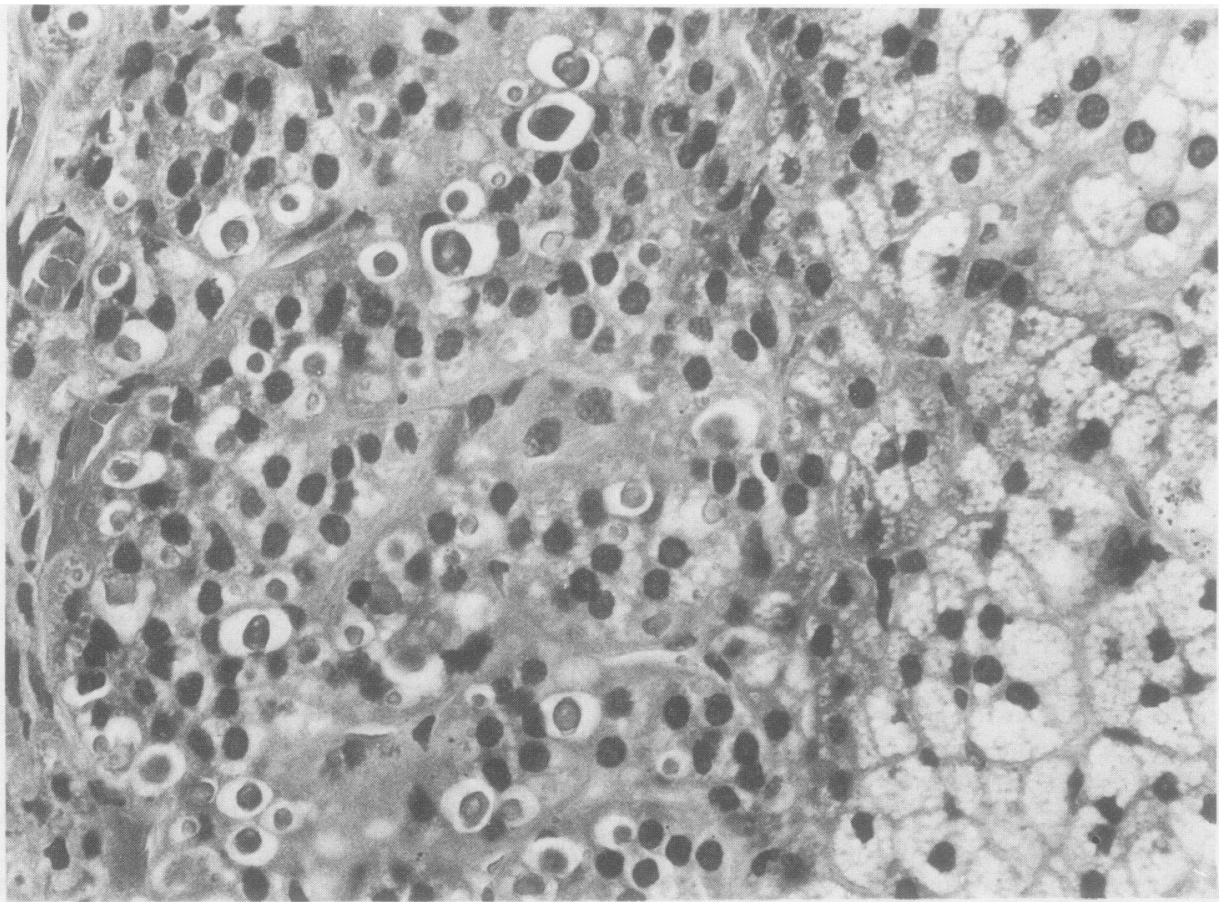

Fig. 4 Hyperplasia of the zona glomerulosa of the adjacent adrenal gland. Zona glomerulosa cells adjacent to the capsule have a higher nuclear cytoplasmic ratio than the underlying zona fasciculata cells and contain numerous spironolactone bodies. Haematoxylin and eosin $\times 700$. 

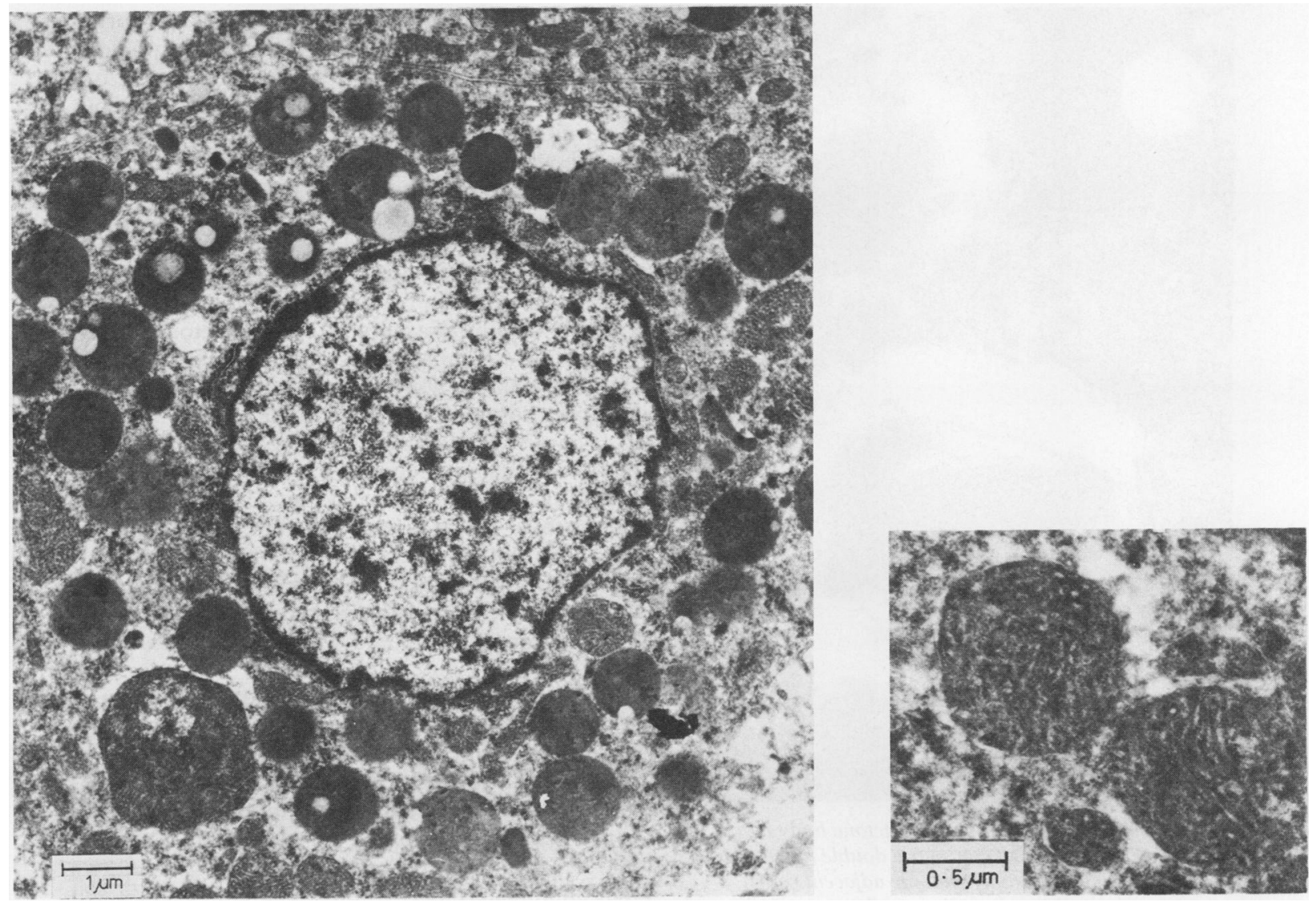

Fig. 5 Electronmicrograph of a compact type cell. Numerous lysosomes, some containing lipid, are present. Microvilli arising from the cell membrane at the upper left can be seen. Mitochondria (see also insert) are tubulo-vesicular.

ised by closely packed concentric lamellae with the appearances of small spironolactone bodies (Fig. 6). Interface cells contained numerous liposomes and mitochondria which were smaller, elongated and with poorly defined internal morphology. Lysosomes were again prominent and other organelles resembled those of the compact cells.

Poor tissue preservation prevented the characterisation of the other cell types observed by light microscopy.

\section{Discussion}

There are several morphological features in the tumour described which are consistent with a secretory function. Some differences from pigmented nodules are shown in Table 3. Most significantly the groups of clear cells interspersed among the compact cells, also observed by Caplan and Virata, constitute a heterogeneity of type in keeping with that of non-pigmented adenomas causing aldosteronism. ${ }^{1}$ is These usually consist of zona glomerulosa, zona fasciculata intermediate and compact type cells in varying proportions. Zona glomerulosa cells may be absent, as in this tumour, or sparsely arranged on the periphery.

Spironolactone bodies have been described in zona glomerulosa ${ }^{16}{ }^{17}$ and compact cells ${ }^{18}$ of aldosteronomas following the preoperative administration of spironolactone. They are a specific marker of aldosterone secreting cells occurring when aldosterone biosynthesis is blocked ${ }^{19}$ and their presence in this tumour therefore supports its secretory function. The observed micronodularity of the adjacent adrenal and the hyperplastic zona glomerulosa have also been described as concomitants of tumorous aldosteronism.' An alternative adenomatous source of aldosterone was not found in the portion of adja- 


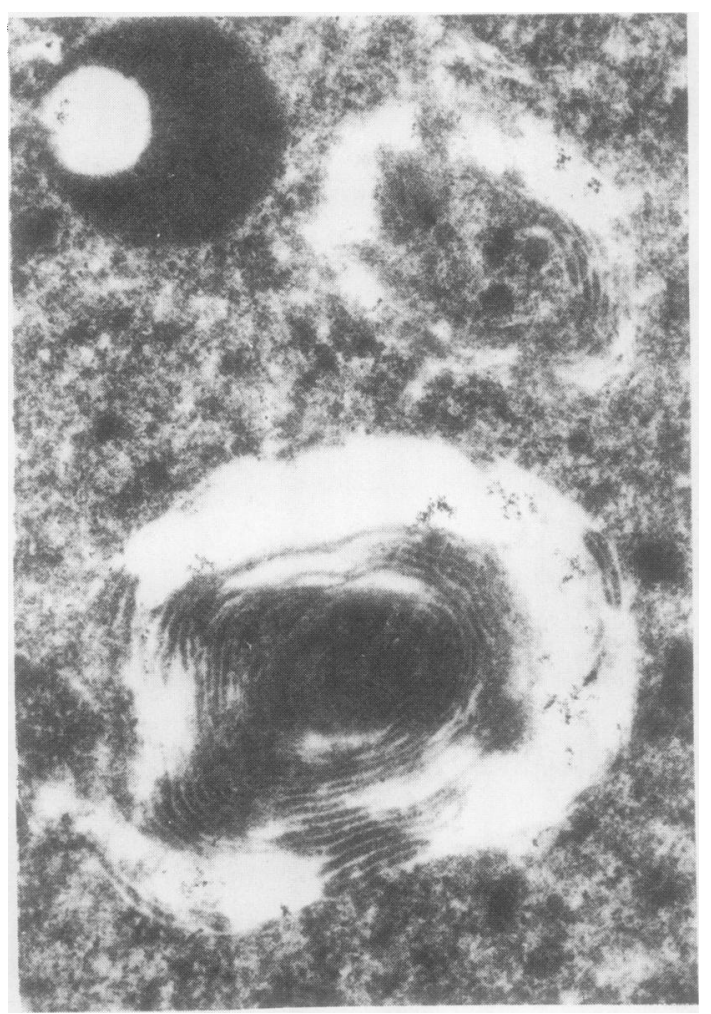

Fig. 6 A fragmented early spironolactone body in a compact cell consisting of concentric double membranes. There is probable continuity with the adjacent rough endoplasmic reticulum. A similar smaller structure is present immediately above it.

Table 3 Comparison of some characteristics of the black adenoma with those of the pigmented nodules described by Robinson et al ${ }^{3}$

\begin{tabular}{lll}
\hline & Black adenoma & Pigmented nodules \\
\hline Age $(\mathrm{y})$ & $30(37$ at operation) & $45-92$ \\
Diameter $(\mathrm{cm})$ & $2 \cdot 2$ & $0 \cdot 1-1 \cdot 5$ \\
Capsule & incomplete & absent \\
Cell type & $\begin{array}{l}\text { compact, interface, } \\
\text { zona fasciculata, } \\
\text { intermediate }\end{array}$ & \\
Cellular pleomorphism & present & present \\
puclear pleomorphism & present & absent \\
pipofuscin & present & present \\
\hline
\end{tabular}

cent adrenal examined.

Non-tumorous aldosteronism with low plasma renin, in which there is bilateral zona glomerulosa hyperplasia with micro- or macro-nodularity, was excluded by a combination of preoperative selenomethylcholesterol scanning, a normal CT scan of the left adrenal, the operative findings and the patient's satisfactory response to surgery.
The identity of the compact cells was supported by the tubulovesicular mitochondrial morphology which is also consistent with non-specific secretory function. ${ }^{8}$ Tubular cristae were often prominent but a definite tendency to a lamellar arrangement as described by Tsuchiyama et $a l^{18}$ and regarded by them as indicating a functional relationship between compact cells and zona glomerulosa cells was not seen in this case. These authors concluded that compact cells were responsible for aldosterone secretion in aldosteronomas on the basis of enzyme histochemistry, the presence of spironolactone bodies and electron microscopic features.

The numerous lysosomes with the staining properties of lipofuscin form a complex with the lipid inclusions which is probably a precursor of pigment bodies. ${ }^{8}$ The large number of lysosomes in this particular tumour are probably the result of a defect within them which does not impair secretory function but results in the characteristic dark colour of this and other black adenomas. ${ }^{1}$ The incidental nature of this defect is supported by the rarity of the black adenoma compared with the non-pigmented adenoma.

An alternative explanation to the one previously described for the relationship between morphology and function of aldosteronomas is provided by Neville and O'Hare.' This is based on the measurement of steroid products of the tumours and of their constituent cells following in vitro culture by high performance liquid chromatography. It proposes that an aldosterone secreting zona glomerulosa cell microadenoma by its expansion alters the adjacent microcirculation and hence hormonal climate of its microenvironment. The result is conversion of some neoplastic zona glomerulosa cells to zona fasciculata cells by way of intermediate cells and finally to compact cells. The steroid products of each cell type tend to promote the sequence and the proportion of zona glomerulosa cells remaining is reduced. This hypothesis would explain the absence or scarcity of the latter cell type in this and other aldosteronomas. There is a concomitant reduction in aldosterone secretion by the tumour which continues to secrete more aldosterone than the hyperplastic zona glomerulosa of the adjacent adrenal. There is no satisfactory explanation for this hyperplasia which is accompanied by a functional atrophy.'

Although the predominance of compact cells can be encompassed by the above hypothesis it does not readily explain the presence of spironolactone bodies in them seen in this case and reported by Tsuchiyama et al. ${ }^{18}$

Despite the difficulties of interpretation, the morphology of the tumour and the adjacent adrenal as reported in this case confirms the association of 
black adenomas with aldosteronism and supports the current concept that they are a rare variant of the commoner non-pigmented aldosteronoma.

We would like to thank Mr HE Berry and Dr DEH Llewelyn for permission to report this case under their care. We are grateful to Mr G Anderson, Mr K Davies and $\mathrm{Mr} \mathrm{R}$ Senkus for their assistance with the light and electron photomicrography. Dr $M$ Driver is thanked for her help and encouragement in the preparation of this paper.

\section{References}

' Neville AM, O'Hare MJ. The human adrenal cortex. Berlin, Heidelberg, New York: Springer-Verlag, 1982.

${ }^{2}$ Macadam RF. Black adenoma of the human adrenal cortex. Cancer 1971;27:116-9.

${ }^{3}$ Robinson MJ, Pardo V, Rywlin AM. Pigmented nodules (black adenomas) of the adrenal: an autopsy study of incidence, morphology and function. Hum Pathol 1972;3:317-25.

4 Bahu RM, Battifora H, Shambaugh G. Functional black adenoma of the adrenal gland: light and electron microscopical study. Arch Pathol 1974;98:139-42.

${ }^{5}$ Visser JW, Boeijinga JK, Meer CD. A functioning black adenoma of the adrenal cortex: a clinico-pathological entity. $J$ Clin Pathol 1974;27:955-9.

${ }^{6}$ Lui KK, Shikata K, Amano T. Black adenoma and pigmented nodules of the adrenal cortex. Fukuoka Igaku Zasshi 1980;71:583-91.

' Zaniewski M, Sheeler R. Cushing's syndrome associated with a functional black adenoma of the adrenal cortex. South Med J 1980;73:1410-2.

${ }^{8}$ Symington T. Functional pathology of the human adrenal gland. Edinburgh and London: Livingstone, 1969.

${ }^{9}$ Sasano N, Ojima M, Masuda T. Endocrinologic pathology of functioning adrenocortical tumours. Pathol Annu 1980;15: 105-41.

${ }^{10}$ Uras A, Budak D, Ariogul O, Gorpe A, Tahsinoglu M. A functioning black adenoma of the adrenal gland. Clin Oncol 1978;4:181-6.

"Caplan RH, Virata RL. Functional black adenoma of the adrenal cortex: a rare cause of primary aldosteronism. Am J Clin Pathol 1974;62:97-103.

${ }^{12}$ Shapiro B, Britton KE, Hawkins LA, Edwards CRW. Clinical experience with 75-Se-selenomethylcholesterol adrenal imaging. Clin Endocrinol 1981;15:19-27.

${ }^{13}$ McDowell EM, Trump BF. Histological fixatives suitable for diagnostic light and electron microscopy. Arch Pathol Lab Med 1976;100:405-14.

${ }^{14}$ Ferriss JB, Neville AM, Brown JJ et al. Hypertension with aldosterone excess and low plasma renin: preoperative distinction between patients with and without adrenocortical tumour. Lancet 1970,ii:995-1000,

is Neville AM, Symington T. Pathology of primary aldosteronism. Cancer 1966; 19: 1854-68.

${ }^{16}$ Cain D R, Van de Velde RL, Shapiro SJ. Spironolactone inclusions in an aldosteronoma. Am J Clin Pathol 1974;61:412-6.

${ }^{17}$ Shrago SS, Waisman J, Cooper PH. Spironolactone bodies in an adrenal adenoma. Arch Pathol 1975;99:416-20.

${ }^{18}$ Tsuchiyama H, Kawai K, Harada T, Shigematsu K, Sugihara H. Functional pathology of aldosterone producing adenoma. Acta Pathol Jpn 1980;30:967-76.

19 Conn JW, Hinerman DL. Spironolactone-induced inhibition of aldosterone biosynthesis in primary aldosteronism: morphological and functional studies. Metabolism 1977;26: 1293-307. 